\title{
Imaging Changes in Synaptic Acetylcholine Availability in Living Human Subjects
}

Irina Esterlis ${ }^{1}$, Jonas O. Hannestad ${ }^{1}$, Frederic Bois ${ }^{1,2}$, R. Andrew Sewell ${ }^{1}$, Rachel F. Tyndale ${ }^{3}$, John P. Seibyl ${ }^{4}$, Marina R. Picciotto ${ }^{1}$, Marc Laruelle ${ }^{1}$, Richard E. Carson ${ }^{2}$, and Kelly P. Cosgrove ${ }^{1,2}$

${ }^{I}$ Department of Psychiatry, Yale University, New Haven, Connecticut; ${ }^{2}$ Department of Radiology, Yale University, New Haven, Connecticut; ${ }^{3}$ Department of Pharmacology and Toxicology and Department of Psychiatry, CAMH and University of Toronto, Toronto, Ontario, Canada; and ${ }^{4}$ Institute for Neurodegenerative Disorders, New Haven, Connecticut

In vivo estimation of $\beta_{2}$-nicotinic acetylcholine receptor availability with molecular neuroimaging is complicated by competition between the endogenous neurotransmitter acetylcholine and the radioligand ${ }^{123} \mid-3-[2(S)$-2-azetidinylmethoxy]pyridine (123I-5-IA). We examined whether binding of ${ }^{123}$ I-5-IA is sensitive to increases in extracellular levels of acetylcholine in humans, as suggested in nonhuman primates. Methods: Six healthy subjects $\left(31 \pm 4\right.$ y) participated in a ${ }^{123}$ |-5-IA SPECT study. After baseline scans, physostigmine (1-1.5 mg) was administered intravenously over $60 \mathrm{~min}$, and 9 additional scans were obtained. Results: We observed a significant reduction in the total volume of distribution after physostigmine administration $(29 \% \pm 17 \%$ in the cortex, $19 \% \pm 15 \%$ in the thalamus, $19 \% \pm 15 \%$ in the striatum, and $36 \% \pm 30 \%$ in the cerebellum; $P<0.05)$. This reduction reflected a combination of a regionspecific $7 \%-16 \%$ decrease in tissue concentration of tracer and a $9 \%$ increase in plasma parent concentration. Conclusion: These data suggest that increases in acetylcholine compete with ${ }^{123}$ I-5-IA for binding to $\beta_{2}$-nicotinic acetylcholine receptor. Additional validation of this paradigm is warranted, but it may be used to interrogate changes in extracellular acetylcholine.

Key Words: brain $\beta_{2}{ }^{*}$-nAChRs; ${ }^{123}$ I-5-IA SPECT; physostigmine; extracellular acetylcholine

J Nucl Med 2013; 54:78-82

DOI: 10.2967/jnumed.112.111922

I n vivo molecular imaging studies of muscarinic and nicotinic acetylcholine receptors have provided substantial contributions to our understanding of disorders related to cholinergic dysfunction but are limited by the lack of a suitable method for measuring fluctuations in brain acetylcholine levels. For example, our evaluation of the $\beta_{2}$-nicotinic acetylcholine receptor $\left(\beta_{2}{ }^{*}\right.$-nAChR) demonstrated significantly lower receptor availability in unmedicated individuals with major depressive disorder than in control subjects (1); however, quantitation of total $\beta_{2}{ }^{*}$-nAChR binding sites

Received Jul. 27, 2012; revision accepted Sep. 27, 2012.

For correspondence or reprints contact: Irina Esterlis, 950 Campbell Ave., West Haven, CT 06516.

E-mail: irina.esterlis@yale.edu

Published online Nov. 15, 2012.

COPYRIGHT @ 2013 by the Society of Nuclear Medicine and Molecular Imaging, Inc. in postmortem brain revealed no differences between major depressive disorder and control samples, suggesting that increased acetylcholine levels in vivo may have resulted in lower $\beta_{2}{ }^{*}$-nAChR availability and apparent lower receptor density.

In vivo imaging of $\beta_{2}{ }^{*}$-nAChRs is possible with the highaffinity radioligand ${ }^{123} \mathrm{I}-3$-[2(S)-2-azetidinylmethoxy]pyridine (123I-5-IA) (2) and SPECT (3). ${ }^{123}$ I-5-IA has slow dissociation from the receptor-ligand complex, a good specificto-nonspecific binding ratio, and high selectivity for $\beta_{2}{ }^{*}$-nAChRs $(3,4)$. ${ }^{123}$ I-5-IA has been used to measure $\beta_{2}{ }^{*}$-nAChR availability in animals (4-O) and humans $(7,8)$; however, there are no published studies demonstrating in vivo measurements of brain levels of acetylcholine in human subjects. Studies on nonhuman primates suggest that competition between acetylcholine and radioligand may be detectable $(9,10)$, and microdialysis studies on rodents suggest an at least 10- to 30-fold increase (depending on dose) in brain acetylcholine levels after acetylcholinesterase inhibitor administration (11). In one study, ${ }^{123}$ I-5-IA binding in the thalamus was decreased $(15 \%)$ after a challenge with a 0.067 $\mathrm{mg} / \mathrm{kg}$ dose of physostigmine and was consistently decreased (14\%-17\%) after a challenge with a $0.2 \mathrm{mg} / \mathrm{kg}$ dose (10).

Here, we used ${ }^{123}$ I-5-IA SPECT to determine whether physostigmine-induced increases in extracellular acetylcholine in the brain compete with ${ }^{123}$ I-5-IA binding in vivo in humans. We hypothesized that physostigmine-induced increases in extracellular acetylcholine would significantly reduce ${ }^{123}$ I-5-IA binding.

\section{MATERIALS AND METHODS}

Six healthy control subjects ( 3 men and 3 women; mean age \pm $\mathrm{SD}, 31 \pm 4$ y) gave written informed consent and completed the study, which was approved by the institutional review boards of Yale University School of Medicine, Veterans Affairs Health Care System, and the University of Toronto. Eligibility was evaluated via a structured interview, behavioral assessments, physical examination, laboratory blood tests, urine drug screening, and an electrocardiogram. Subjects had never smoked; had no life-time psychiatric, neurologic, or medical history; and had no contraindications for undergoing an MRI scan and a ${ }^{123}$ I-5-IA SPECT scan on the same day.

Mood symptoms were measured with the Center for Epidemiological Studies Depression Scale (12) and the Beck Depression Inventory (13). State and trait anxiety symptoms were measured 
with the Spielberger State-Trait Anxiety Inventory (14). All tests were administered at intake and on the scanning day (before and after physostigmine administration).

MRI was performed on a 3-T Magnetom Trio with Tim technology (Siemens) running Numaris/4 software (version: syngo MR B17) to guide placement of regions of interest for SPECT scans (series 1: 3plane localizer; series 2: sagittal 3-dimensional turbo fast low-angle shot, 250-mm field of view, 1-mm-thick slices, 176 slices in total, echo time of $3.53 \mathrm{~ms}$, repetition time of 2,500 ms, inversion time of 1,100 $\mathrm{ms}$, flip angle of 7,256 $\times 256$ matrix, and 2 signal averages).

${ }^{123}$ I-5-IA was synthesized and administered for the duration of the study as described previously (7) using a bolus plus a constant infusion ( $7.3 \pm 0.2 \mathrm{~h}$ ) with a total injected dose (accounting for decay) of 390.2 $\pm 13.2 \mathrm{MBq}$. Six hours after injection of ${ }^{123}$ I-5-IA, a simultaneous transmission emission scan and 3 equilibrium 30-min emission scans (90 min total) were obtained on a Prism 3000 XP SPECT camera (Phillips). Subjects were administered glycopyrrolate $(0.2 \mathrm{mg}$, intravenously) to minimize peripheral muscarinic side effects, followed by administration of physostigmine (a reversible acetylcholinesterase inhibitor that crosses the blood-brain barrier) over $1 \mathrm{~h}$ (1-1.5 $\mathrm{mg}$, intravenously). Thereafter, up to 3 sets of 30-min emission scans were acquired (each set $90 \mathrm{~min}$ in duration, with a 20 - to 30 -min break between each set. In subject 5, the ${ }^{123}$ I-5-IA infusion was interrupted after the collection of 5 postphysostigmine scans; thus, data thereafter are not shown. In the other 5 subjects, all 9 postphysostigmine scans were collected). Venous blood samples were collected before and after physostigmine administration to correct for individual differences in radiotracer metabolism and protein binding. Pulse and blood pressure were measured before and after injection of ${ }^{123}$ I-5-IA and before and after physostigmine administration.

SPECT images were analyzed as described previously (7). Regional ${ }^{123}$ I-5-IA uptake $\left(\beta_{2}{ }^{*}\right.$-nAChR availability) was calculated as total volume of distribution $\left(V_{\mathrm{T}} / f_{\mathrm{p}}\right)$, where $V_{\mathrm{T}}$ is brain regional activity divided by metabolite-corrected plasma activity and $f_{\mathrm{p}}$ is the free fraction of parent in plasma. Plasma for $f_{\mathrm{p}}$ calculation was collected at 4 time points and applied to calculate the corresponding $V_{\mathrm{T}} / f_{\mathrm{p}}$. The first was before ${ }^{123}$ I-5-IA administration (baseline), the second was immediately before physostigmine administration, the third was immediately after physostigmine administration, and the fourth was at the end of the last set of postdrug scans. Specifically, $f_{\mathrm{p}}$ values from time points 1 and 2 were averaged and applied to baseline $V_{\mathrm{T}}$ to estimate baseline $V_{\mathrm{T}} / f_{\mathrm{p}} ; f_{\mathrm{p}}$ from time point 3 (immediately after physostigmine administration) was applied to $V_{\mathrm{T}}$ from the first and second postphysostigmine scanning sessions to estimate $V_{\mathrm{T}} / f_{\mathrm{p}}$ for those time points; and $f_{\mathrm{p}}$ from time point 4 was applied to the last scanning session. The regions studied were frontal, parietal, anterior cingulate, temporal, and occipital cortices (averaged to obtained a single cortical value); striatum; thalamus; and cerebellum. The change in radioligand binding to $\beta_{2}{ }^{*}$-nAChRs was calculated as the percentage difference between $V_{\mathrm{T}} / f_{\mathrm{p}}$ before and $V_{\mathrm{T}} / f_{\mathrm{p}}$ after physostigmine administration for each postdrug SPECT scan. To demonstrate the use of previously calculated nondisplaceable binding $\left(V_{\mathrm{ND}} / f_{\mathrm{P}}\right)(15)$ and estimate specific radioligand binding $\left(B P_{f}\right)$, we subtracted a fixed value (19.4 $\left.\mathrm{mL} \cdot \mathrm{cm}^{-3}\right)$ of $V_{\mathrm{ND}} / f_{\mathrm{P}}$ from $V_{\mathrm{T}} / f_{\mathrm{p}}$ for each brain region and scan.

All statistical analyses were performed using SPSS, version 19.0 (IBM). Statistical significance was set at a $P$ value of 0.05 or less, 2-tailed. Repeated measures of ANOVA ( $\mathrm{df}=5$ ) were used to assess within-subject differences in pharmacokinetic parameters and mood variables before and after physostigmine administration. SD was calculated for all outcome variables (Table 1) and is represented as error bars in Figure 1.

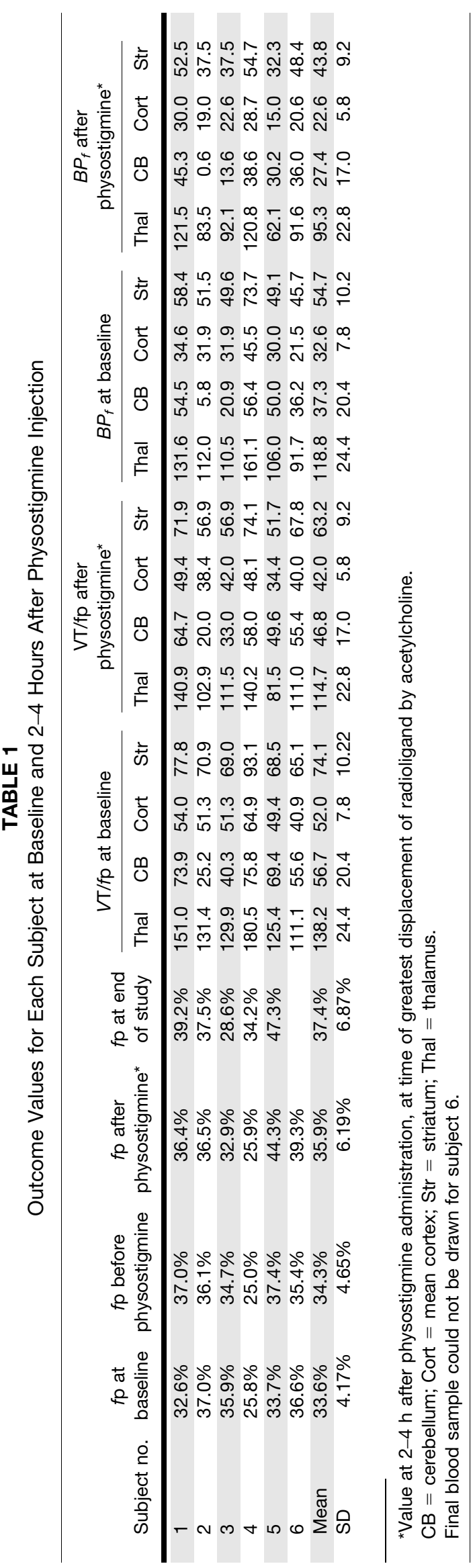


FIGURE 1. First point in each graph represents baseline data obtained starting $6 \mathrm{~h}$ after beginning of tracer infusion, when state of equilibrium was achieved, and provided baseline specific binding. After completion of baseline scans, physostigmine was administered intravenously (1.0-1.5 mg over $1 \mathrm{~h}$ ). At onset of physostigmine infusion, scanning was resumed for up to $9 \mathrm{~h}$. Bars represent SEM. (A) Plasma ${ }^{123}|-5-| A$ concentration $(\mathrm{kBq} / \mathrm{mL})$ (total parent) measured during ${ }^{123}$ I-5-IA constant infusion in healthy volunteers. After physostigmine administration, there was significant $9 \%$ increase in mean plasma ${ }^{123}$ I-5-IA concentration as compared with before physostigmine administration. (B) Tissue ${ }^{123} \mid-5-I A$ concentration $\left(\mathrm{kBq} / \mathrm{cm}^{3}\right)$ in thalamus, striatum, cortex, and cerebellum measured during ${ }^{123} \mid-5-I A$ constant infusion. We observed 7\%-16\% region-specific decrease in ${ }^{123} \mid-5-I A$ tissue concentration after physostigmine challenge. (C) ${ }^{123} \mathrm{I}-5-\mathrm{IA} V_{\mathrm{T}} / f_{\mathrm{p}}$ in thalamus, striatum, cortex, and cerebellum measured during ${ }^{123} /-5-I A$ constant infusion. $V_{T} / f_{p}$ values measured after physostigmine infusion were significantly reduced $(14 \%-18 \%$ regionspecific), compared with baseline values. (D) ${ }^{123} \mid-5-I A B P_{f}$ in thalamus, striatum, cortex, and cerebellum measured during ${ }^{123} \mid-5-I A$ constant infusion. $B P_{f}$ values measured after physostigmine infusion were significantly reduced (19\%-36\% region-specific), compared with baseline values.

\section{RESULTS}

Nonsmoking status was verified by negligible urine cotinine ( $0 \eta \mathrm{g} / \mathrm{mL})$, plasma cotinine $(<2 \eta \mathrm{g} / \mathrm{mL})$, and nicotine $(<1.0 \eta \mathrm{g} / \mathrm{mL})$ levels and exhaled carbon monoxide $(0.7 \pm$ $0.8 \mathrm{ppm})$. There were no significant differences in subjects' mood or anxiety before and after physostigmine administration $(P>0.2)$.

Administration of physostigmine did not significantly alter free fraction $(P>0.2)$ but resulted in significantly increased ${ }^{123}$ I-5-IA total plasma parent activity for all subjects $(9.1 \% \pm$ $8.6 \%, t=-2.56, P=0.05,1 \mathrm{~h}$ after a challenge, stable thereafter; Fig. 1A) and significantly increased free parent activity $(9.9 \% \pm 7.7 \%, t=-3.1, P=0.03)$ at $1 \mathrm{~h}$ after a challenge but not thereafter $(t=-1.2, P=0.30,6 \mathrm{~h}$ after a challenge).

Equilibrium ${ }^{123}$ I-5-IA binding $(<5 \%$ change in receptor availability/h), was reached $6-8 \mathrm{~h}$ after injection (average change across subjects: $2.7 \% \pm 1.7 \% / \mathrm{h}$ in the thalamus, $3.6 \% \pm 2.2 \% / \mathrm{h}$ in the striatum, $2.5 \% \pm 2.5 \% / \mathrm{h}$ in the cortex, and $1.7 \% \pm 1.6 \% / \mathrm{h}$ in the cerebellum). ${ }^{123}$ I-5-IA tissue concentration was reduced after physostigmine, with the peak reduction reached $2-4 \mathrm{~h}$ after a challenge (Fig. 1B), the same time point for the greatest decrease in ${ }^{123}$ I-5-IA binding after nicotine administration $(15,16)$. A reduction in ${ }^{123}$ I-5-IA tissue concentration was observed in all brain regions $2-4 \mathrm{~h}$ after a challenge: thalamus, $7.8 \% \pm 4.7 \%$; striatum, $7.0 \% \pm 0.9 \%$; mean cortex, $12.7 \% \pm 18.1 \%$; and cerebellum, $16.5 \% \pm 13.6 \%$.

Administration of physostigmine significantly reduced the total volume of distribution of ${ }^{123}$ I-5-IA at $2-4 \mathrm{~h}$ after physostigmine administration. The peak average decrease in $V_{\mathrm{T}} / f_{\mathrm{p}}$ was $18 \% \pm 11 \%$ in cortical regions $\left(F_{5}=15.4, P=\right.$ $0.01), 17 \% \pm 12 \%$ in the thalamus $\left(F_{5}=11.3, P=0.02\right)$, $14 \% \pm 11 \%$ in the striatum $\left(F_{5}=11.0, P=0.02\right)$, and $17 \% \pm$ $10 \%$ in the cerebellum $\left(F_{5}=10.4, P=0.02\right)$ (Figs. 1C and $2 \mathrm{~A}$ ).

Subtraction of $V_{\mathrm{ND}} / f_{\mathrm{p}}$ revealed a greater percentage reduction in specific binding of ${ }^{123}$ I-5-IA. The peak average decrease in $B P_{f}$ was $29 \% \pm 17 \%$ in cortical regions $\left(F_{5}=\right.$ $15.4, P=0.01), 19 \% \pm 15 \%$ in the thalamus $\left(F_{5}=11.3\right.$, $P=0.02), 19 \% \pm 15 \%$ in the striatum $\left(F_{5}=11.0, P=\right.$ $0.02)$, and $36 \% \pm 30 \%$ in the cerebellum $\left(F_{5}=10.4, P=\right.$ 0.02) (Figs. 1D and 2).

There was a significant decrease in pulse rate after physostigmine administration $(12.3 \% \pm 13.3 \% ; P=0.08)$ but no significant changes in blood pressure $(P>0.7)$.

\section{DISCUSSION}

We evaluated whether increases in extracellular levels of the endogenous neurotransmitter acetylcholine compete with ${ }^{123}$ I-5-IA binding to $\beta_{2}{ }^{*}$-nAChRs. The goal of this study was to establish a novel paradigm to interrogate the cholinergic system in vivo in humans and to provide a more comprehensive interpretation of our $(1,17)$ and other's $(18)$ findings in populations with compromised cholinergic systems. Physostigmine administration resulted in a significant decrease in total ${ }^{123}$ I-5-IA binding, suggesting that ${ }^{123}$ I-5-IA is sensitive to extracellular acetylcholine levels. This reduction in ${ }^{123}$ I-5-IA binding is similar to that achieved after smoking a cigarette from which the nicotine has been 


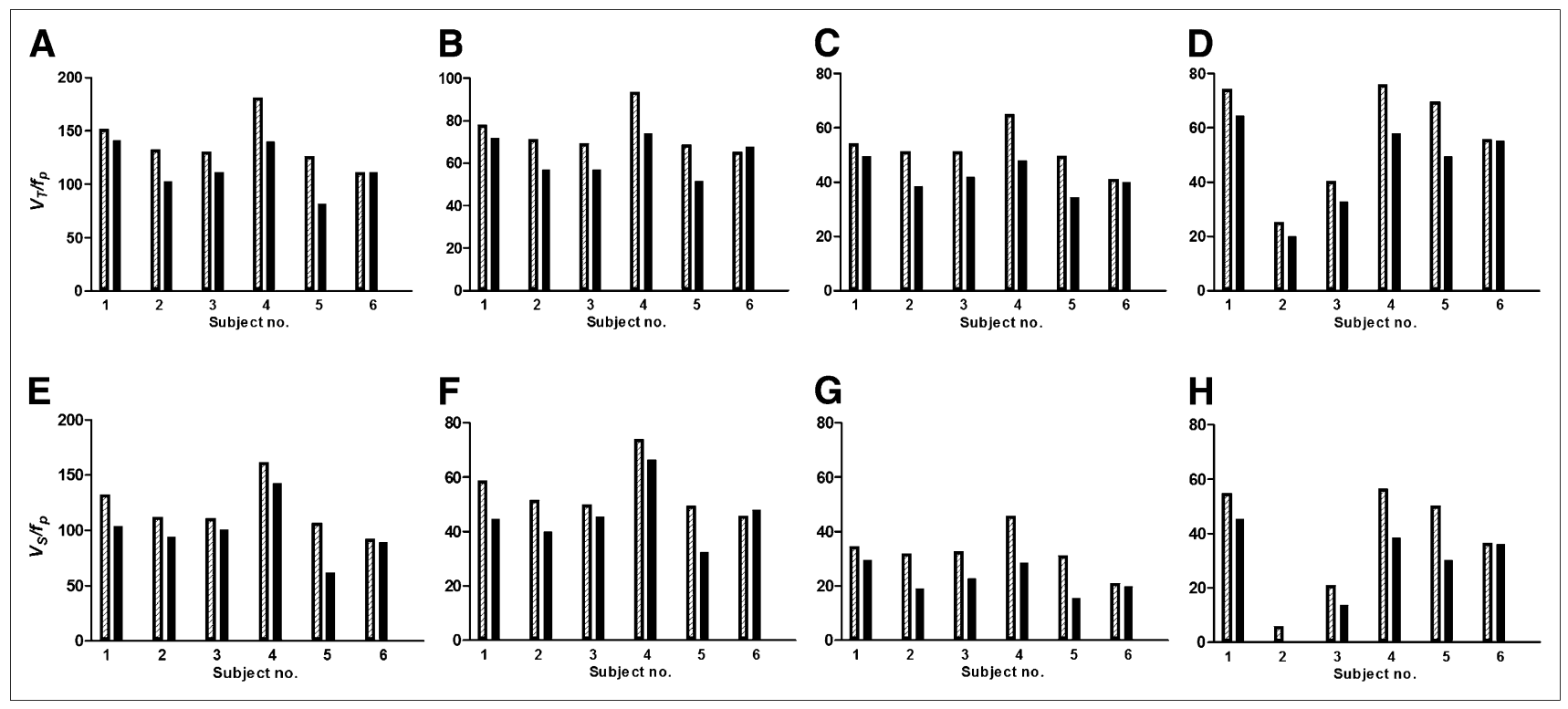

FIGURE 2. (A-D) $\beta_{2}{ }^{*}-n A C h R$ availability $\left(V_{T} / f_{\mathrm{P}}\right)$ before (hatched bars) and after (black bars) physostigmine injection for each subject. For thalamus (A), percentage displacement of $5-\mathrm{IA}$ for subjects $1-6$ was $-7 \%,-22 \%,-14 \%,-22 \%,-35 \%$, and $-0 \%$. For striatum (B), percentage displacement was $-8 \%,-20 \%,-18 \%,-20 \%,-25 \%$, and $-4 \%$. For cortex (C), percentage displacement was $-9 \%,-25 \%$, $-18 \%,-26 \%,-30 \%$, and $-2 \%$. For cerebellum (D), percentage displacement was $-12 \%,-20 \%,-18 \%,-23 \%,-28 \%$, and $0 \%$. (E-H) $B P_{f}$ before (hatched bars) and after (black bars) physostigmine injection for each subject. For thalamus (E), percentage displacement of 5-IA for subjects $1-6$ was $-8 \%,-25 \%,-17 \%,-25 \%,-41 \%$, and $0 \%$. For striatum (F), percentage displacement was $-10 \%,-27 \%,-24 \%$, $-26 \%,-34 \%$, and $+5 \%$. For cortex $(\mathrm{G})$, percentage displacement was $-13 \%,-40 \%,-29 \%,-36 \%,-50 \%$, and $-6 \%$. For cerebellum $(\mathrm{H})$, percentage displacement was $-17 \%,-90 \%,-35 \%,-32 \%,-40 \%$, and $-1 \%$.

removed ((19) and unpublished data from our group). Such cigarettes have only $0.05 \mathrm{mg}$ of nicotine, equivalent to smoking about 1 puff from a regular cigarette. However, given that nicotine is a direct agonist at $\beta_{2}{ }^{*}$-nAChRs and has high affinity for the receptor, and physostigmine-induced radioligand displacement has an indirect action, it is not surprising that administration of a high dose of physostigmine leads to displacement of ${ }^{123}$ I-5-IA comparable to that from administration of $0.05 \mathrm{mg}$ of nicotine.

The degree of reduction of ${ }^{123}$ I-5-IA binding in the thalamus after a physostigmine challenge is in line with the findings of a previous study on nonhuman primates (10), although the amount of injected physostigmine was 10 -fold less in the present human study. The similarity in the decrease of radioligand binding may be attributed to lower levels of acetylcholine release in anesthetized nonhuman primates than in conscious humans or to physiologic differences between species. The observed decrease in ${ }^{123}$ I-5-IA binding here and in the previous study (10) was due to a combination of increases in ${ }^{123}$ I-5-IA plasma concentration and a reduction in ${ }^{123}$ I-5-IA tissue concentration. Thus, administration of physostigmine appears to alter radioligand distribution throughout the body, affecting tracer levels in the blood. Specifically, the increase in acetylcholine due to administration of physostigmine occurs throughout the body, and thus the peripheral nAChR binding sites previously available for binding of ${ }^{123}$ I-5-IA are now also occupied by acetylcholine. The displacement of ${ }^{123}$ I-5-IA in the body likely causes more free radioligand to circulate in the plasma. Thus, the tissue concentration alone is not an accurate measure for the evaluation of physostigmineinduced acetylcholine displacement of ${ }^{123}$ I-5-IA, and total volume of distribution or specific ligand binding should be used in this paradigm.

There were several limitations to this study. First, physostigmine may have an allosteric effect on radioligand binding to $\beta_{2} *$-nAChRs; however, physostigmine did not alter ${ }^{123}$ I-5-IA binding in rat in vitro studies and had a significantly lower affinity for $\beta_{2}{ }^{*}$-nAChR than did ${ }^{123}$ I-5-IA $(25,000 \mathrm{nM}$ for physostigmine vs. $0.010 \mathrm{nM}$ for ${ }^{123}$ I-5-IA) (4). Thus, competition between physostigmine and ${ }^{123}$ I-5-IA for binding to the receptor is not a likely explanation for the observed outcome of decreased ${ }^{123} \mathrm{I}-5$ IA binding after physostigmine administration. Second, the use of $V_{\mathrm{ND}} / f_{\mathrm{p}}$ obtained from a previous sample of control smokers may not be applicable to a study of nonsmokers. Further, the use of a fixed value for nondisplaceable binding across regions may not accurately reflect the observed regional differences in specific binding, especially for regions with lower levels of specific binding. Specifically, the change in thalamic $V_{\mathrm{T}} / f_{\mathrm{p}}$ and $B P_{f}$ was $16 \%$ and $19 \%$, respectively, whereas the change in a lower-binding region (i.e., cerebellum) was $17 \%$ and $36 \%$, respectively. Thus, $B P_{f}$ values were reported with the purpose of showing how the estimate of $V_{\mathrm{ND}} / f_{\mathrm{p}}$ may be used in future studies. Finally, the small sample size allows drawing only preliminary conclusions and limits examination of sex or age differences. 


\section{CONCLUSION}

We developed a paradigm to interrogate the acetylcholine system in vivo in human subjects and observed a significant decrease in total binding of ${ }^{123}$ I-5-IA after a physostigmine challenge, consistent with an increase in endogenous extracellular acetylcholine levels. This imaging tool may have enormous potential to facilitate the development of innovative medicines aimed at modulating the cholinergic system.

\section{DISCLOSURE}

The costs of publication of this article were defrayed in part by the payment of page charges. Therefore, and solely to indicate this fact, this article is hereby marked "advertisement" in accordance with 18 USC section 1734. Salary support was provided by a VA Career Award and K01MH092681 (Dr. Estelis), MH077681 (Dr. Picciotto), K12DA00167 (Dr. Hannestad), and K01DA20651 (Dr. Cosgrove). Studies were supported by the VA National Center for PTSD and Yale University. Dr. Seibyl has equity interest in Molecular Neuroimaging, LLC. Dr. Tyndale has participated in 1-day advisory meetings for Novartis and McNeil. Dr. Laruelle was a consultant for Amgen, Pfizer, and Roche and a GlaxoSmithKline shareholder at the time of completion of this study and is now a full-time employee of UCB Pharma. No other potential conflict of interest relevant to this article was reported.

\section{ACKNOWLEDGMENTS}

We thank the technologists at the Institute for Neurodegenerative Disorders for conducting the scanning protocol and Louis Amici (Yale University) for metabolite and protein binding analyses of the radiotracer.

\section{REFERENCES}

1. Saricicek A, Esterlis I, Maloney K, et al. Persistent $\beta 2 *$-nicotinic acetylcholinergic receptor dysfunction in major depressive disorder. Am J Psychiatry. 2012;169:851-859.
2. Abreo MA, Lin N-H, Garvey D, et al. Novel 3-pyridyl ethers with subnanomolar affinity for central neuronal nicotinic acetylcholine receptors. J Med Chem. 1996;39:817-825.

3. Vaupel DB, Mukhin A, Kimes A, Horti A, Koren A, London E. In vivo studies with [ ${ }^{125}$ I] 5 -IA 85380 , a nicotinic acetylcholine receptor radioligand. Neuroreport. 1998;9:2311-2317.

4. Mukhin AG, Gundisch D, Horti A, et al. 5-iodo-A-85830, an $\alpha 4 \beta 2$ subtypeselective ligand for nicotinic acetylcholine receptors. Mol Pharmacol. 2000; 57:642-649.

5. Fujita M, Tamagnan G, Zoghbi S, et al. Measurement of $\alpha_{4 \beta 2}$ nicotinic acetylcholine receptors with [ ${ }^{123}$ I] 5-I-A85830 SPECT. J Nucl Med. 2000;41:1552-1560.

6. Chefer S, Horti A, Lee K, et al. In vivo imaging of brain nicotinic acetylcholine receptors with 5 -[ $\left.{ }^{123} \mathrm{I}\right]$ iodo-A-85830 using single photon emission computed tomography. Life Sci. 1998;63:PL355-PL360.

7. Staley JK, van Dyck CH, Weinzimmer D, et al. Iodine-123-5-IA-85380 SPECT measurement of nicotinic acetylcholine receptors in human brain by the constant infusion paradigm: feasibility and reproducibility. J Nucl Med. 2005;46:1466-1472.

8. Fujita M, Seibyl J, Vaupel D, et al. Whole body biodistribution, radiationabsorbed dose and brain SPET imaging with [ $\left.{ }^{123} \mathrm{I}\right] 5-\mathrm{I}-\mathrm{A}-85830$ in healthy human subjects. Eur J Nucl Med Mol Imaging. 2002;29:183-190.

9. Valette H, Bottlaender M, Dollé F, Coulon C, Ottaviani M, Syrota A. Acute effects of physostigmine and galantamine on the binding of $\left[{ }^{18} \mathrm{~F}\right]$ fluoro-A85380: a PET study in monkeys. Synapse. 2005;56:217-221.

10. Fujita M, Al-Tikriti M, Tamagnan G, et al. Influence of acetylcholine levels on the binding of a SPECT nicotinic acetylcholine receptor ligand [ $\left.{ }^{123} \mathrm{I}\right] 5-\mathrm{I}-\mathrm{A}-$ 85380. Synapse. 2003;48:116-122.

11. Noori HR, Fliegel S, Brand I, Spanagel R. The impact of acetylcholinesterase inhibitors on the extracellular acetylcholine concentrations in the adult rat brain: a meta-analysis. Synapse. 2012;66:893-901.

12. Radloff L. The CES-D scale: a self-report depression scale for research in the general population. Appl Psychol Meas. 1977;1:385-401.

13. Beck AT, Ward C, Mendelsohn M, Erbaugh J. An inventory for measuring depression. Arch Gen Psychiatry. 1961;4:561-571.

14. Spielberger C, Corsuch R, eds. Manual for state-trait anxiety inventory. Palo Alto CA: Consulting Psychologists Press; 1983.

15. Esterlis I, Cosgrove K, Batis J, et al. Quantification of smoking induced occupancy of $\beta 2$-nicotinic acetylcholine receptors: estimation of nondisplaceable binding. J Nucl Med. 2010;51:1226-1233.

16. Esterlis I, Mitsis E, Batis J, et al. Brain $\beta 2 *$-nicotinic acetylcholine receptor occupancy after use of a nicotine inhaler. Int $J$ Neuropsychopharmacol. 2011;14:389-398.

17. D'Souza DC, Esterlis I, Carbuto M, et al. Lower $\beta 2 *$-nicotinic acetylcholine receptor availability in smokers with schizophrenia. Am J Psychiatry. 2012; 169:326-334.

18. Ellis JR, Villemagne V, Nathan P, et al. Relationship between nicotinic receptors and cognitive function in early Alzheimer's disease: a $2-\left[{ }^{18} \mathrm{~F}\right]$ fluoro-A-85380 PET study. Neurobiol Learn Mem. 2008;90:404-412.

19. Brody AL, Mandelkern M, Costello M, et al. Brain nicotinic cetylcholine receptor occupancy: effect of smoking a denicotinized cigarette. Int J Neuropsychopharmacol. 2009;12:305-316. 